\title{
Space Suit Radiator Performance in Lunar and Mars Environments
}

\author{
James Nabity, Georgia Mason, Robert Copeland and Kerry Libberton \\ TDA Research, Inc
}

\author{
Ryan Stephan, Luis Trevino and Heather Paul \\ NASA Johnson Space Center
}

Copyright @ 2005 SAE International

\begin{abstract}
During an ExtraVehicular Activity (EVA), both the heat generated by the astronaut's metabolism and that produced by the Portable Life Support System (PLSS) must be rejected to space. The heat sources include the heat of adsorption of metabolic $\mathrm{CO}_{2}$, the heat of condensation of water, the heat removed from the body by the liquid cooling garment and the load from the electrical components. Although the sublimator hardware to reject this load weighs only $1.58 \mathrm{~kg}(3.48$ $\mathrm{lbm})$, an additional $3.6 \mathrm{~kg}(8 \mathrm{lbm})$ of water are loaded into the unit, most of which is sublimated and lost to thus become the single largest expendable during an eighthour EVA. We can significantly reduce the amount of expendable water consumed in the sublimator by using a radiator to reject heat from the Astronaut during an EVA.
\end{abstract}

Last year we reported on the design and initial operational assessment tests of our novel radiator designated the Radiator And Freeze Tolerant heat eXchanger (RAFT-X). Herein, we report on tests conducted in the NASA Johnson Space Center Chamber E Thermal Vacuum Test Facility. Up to $260 \mathrm{~W}$ (900 Btu/h) of heat were rejected in Lunar and Mars environments with temperatures as cold as $-170^{\circ} \mathrm{C}(-$ $275^{\circ} \mathrm{F}$ ). Further, the RAFT-X endured several freeze / thaw cycles and in fact, the heat exchanger was completely frozen three times without any apparent damage to the unit.

\section{INTRODUCTION}

At present, both the astronaut's metabolic heat and that produced by the Portable Life Support System (PLSS) are rejected to space by a sublimator that consumes up to $3.6 \mathrm{~kg}(8 \mathrm{lbm})$ of water [1]; the single largest expendable during an eight-hour extravehicular activity (EVA) [2]. Unfortunately, this will not be acceptable for moon and interplanetary missions where resupply is difficult. The amount of water lost to sublimation can be greatly reduced by radiating most of the heat load to the ambient environment.

While the advantages of radiators have long been recognized (they can operate effectively in earth orbit, trans-Lunar, trans-Martian, and in most Lunar and Mars environments), they have a problem that has so far prevented their use: current simple designs reject heat at a relatively steady rate, but the rate of heat generation by the astronaut can vary from 70 to $730 \mathrm{~W}$ [3]. Without a way to continuously adjust the heat removal rate, the astronaut will alternate between heat stroke and frostbite conditions.

It has long been known that a radiator can be "turneddown" by sequentially allowing tubes that carry the water to the radiator to freeze. When a tube freezes, the temperature of the radiating area around it drops, and the heat rejection rate drops as well. The problem with the freezable radiators developed to date is that they are far too heavy, since they used heavy walled tubes to prevent bursting during freeze/thaw cycles. Further, in past freezable designs, the entire surface of the PLSS had to be thick enough to conduct enough heat several inches to melt the adjacent frozen tubes.

Cross, Trevino, and Laubach [4] report a system in which the heat flowing to the radiator was decreased by creating a small gap between the radiator and the water loop. When the heat load was high, the gap was filled with a gas to increase the conductance. When the heat load was low, the gap was vented to space, the heat transfer rate was decreased (vacuum is a very good insulator), and the heat rejection rate dropped. However, the weight of the system was $20 \mathrm{~kg}$ (44 lbm) compared to $7.2 \mathrm{~kg}(15.9 \mathrm{lbm})$ for the current system. Additionally, because of heat leaks, there was only a $\sim 25 \%$ reduction in heat rejection in a cold environment.

In order to reduce the system weight, TDA developed a radiator able to serve multiple functions. Specifically, it can: 1) reject heat from the PLSS, 2) provide structural resistance to impacts (to cover the components of the 
PLSS and protect them from damage by micrometeoroids or accidents), and 3) provide a rigid structure on which to mount equipment. This approach provides the needed performance with no additional weight penalty. Recently, a flight-weight prototype was built by TDA (Figure 1) and then tested in the NASA Johnson Space Center Chamber E Thermal Vacuum Facility. In this paper, we present the experimental performance data obtained in Lunar and Mars environments. NASA JSC then used the data to validate models able to estimate the performance in other Lunar environments.

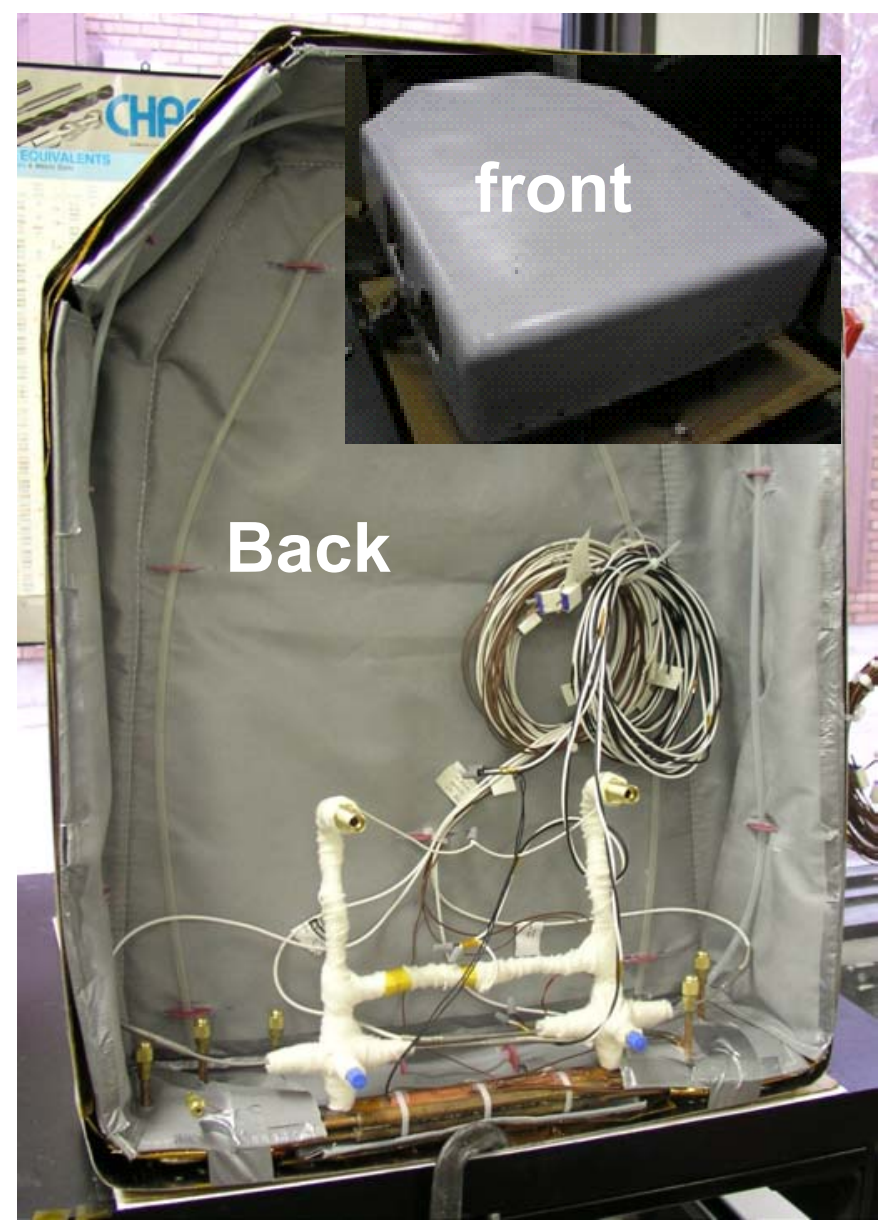

Figure 1. RAFT-X prototype radiator.

\section{RAFT-X CONCEPT DESCRIPTION}

As shown in Figure 2, warm water from the astronaut's liquid cooling garment (LCG) enters a freeze tolerant heat exchanger and transfers heat to the refrigerant loop. The refrigerant boils in the evaporator section of the heat exchanger and vapor moves up the heat pipe that is located on the radiator panel of the PLSS backpack. As heat is rejected by radiation, the vapor condenses and travels back to the evaporator. There are no moving parts (i.e. pumps) and the system is completely passive.

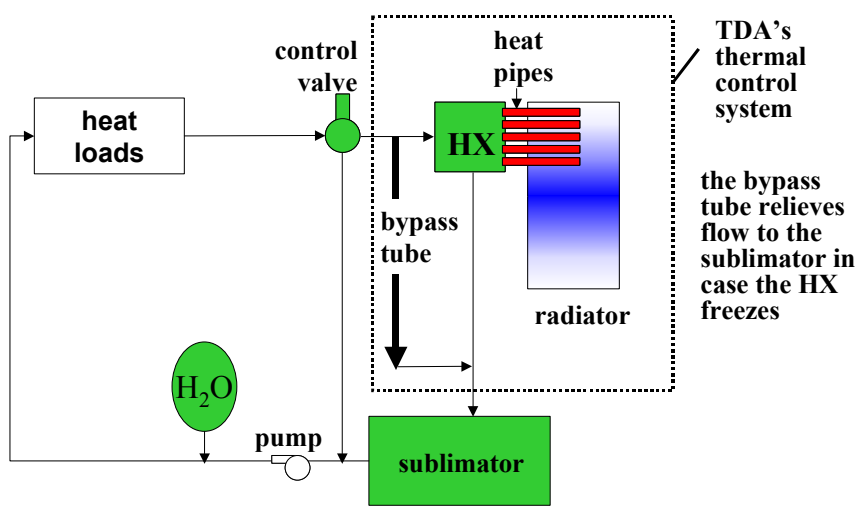

Figure 2. Process flow diagram.

A heat exchanger can accommodate the variable heat load from the crewmember, if it can be selectively frozen to reduce the fin surface area during low load operation. Making it freeze trap tolerant ensures effective and safe operation at any load. Under low metabolic load, the control valve reduces the water flow to the heat exchanger. In cold environments the heat exchanger drops below the freeze point of water and passively controls the heat rejection rate by allowing the coldest water flow passages in the heat exchanger to freeze. As the water in the heat exchanger freezes, sections of the heat exchanger become inactive, preventing heat rejection to the heat pipes that are in contact with those surfaces of the heat exchanger. At the minimum heat load all of the water passages freeze, except for the bypass tube (again, see Figure 2) that will always flow some water to the sublimator and thereby provide continuous and uninterrupted cooling even when the heat exchanger transfers little to no heat. The loop heat pipes will not freeze even if the PLSS is facing deep space.

As Nabity, et al. [3] previously reported, there are a number of advantages to this concept. First, using two separate fluid loops allows us to take advantage of the thermal properties of a refrigerant fluid without altering the LCG. The fluid selection has no impact on the rest of the EMU system. Further, because the heat pipe fluid loops are independent from one another and are also separate from the water loop, a puncture to one of the heat pipes is not a life-threatening emergency. If the refrigerant in the punctured heat pipe drains out, the water-cooling loop is not affected. The other heat pipes, as well as the sublimator, still remain operational to provide the needed cooling. Perhaps most importantly the heat exchanger is small, so the increase in weight to make the heat exchanger freezable is far less than the increase in weight of making the much larger radiator fully freezable.

The copper heat exchanger (Figure 3 ) contains both the water loop and the evaporators for the refrigerant system. Its dimensions are $4.17-\mathrm{cm}$ wide $\times 2.2-\mathrm{cm}$ high $x 25.4-\mathrm{cm}$ long and it weighs $1.48 \mathrm{~kg}(3.26 \mathrm{lbm})$. 


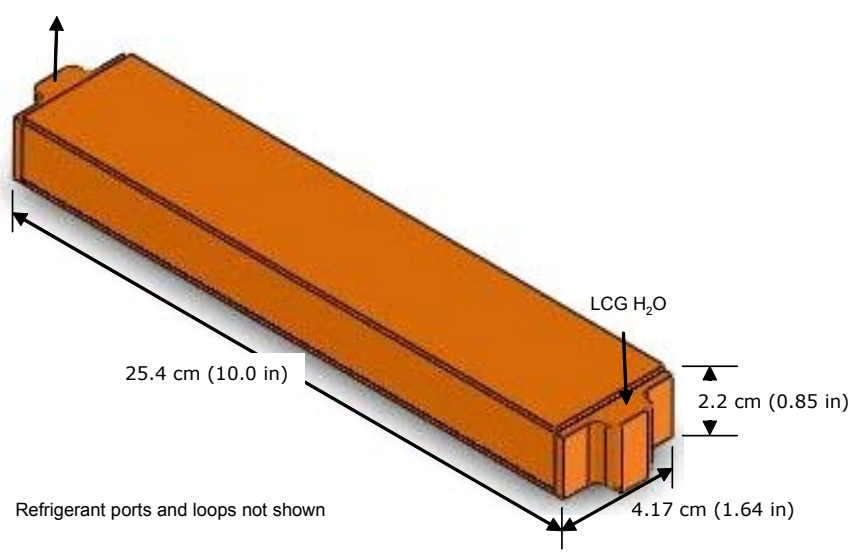

Figure 3. Box size of the freeze tolerant heat exchanger.

The radiator / PLSS shell was constructed from $1.59 \mathrm{~mm}$ (0.0625-inch) thick 6061-T6 aluminum sheet and painted with a highly emissive Aeroglaze coating. The Al 6061T6 radiator wall thickness was sized to provide the needed impact resistance for use on Mars [6], even though the thermal conductance would have been good enough with much thinner material. TDA installed a 3.05 $\mathrm{mm}$ (0.12-inch) thick 7-ply multi-layer insulation for low earth orbit and moon environments. Next, were two $6.35 \mathrm{~mm}(1 / 4$-inch) thick layers of Aspen aerogel SpaceLoft TM AR3103. The aerogel is specifically needed for use in the Mars atmosphere and can also work well in vacuum, but is heavier and thicker than the multilayer insulation. Both were installed to avoid test downtime otherwise needed to repressurize the chamber, swap the MLI and aerogel insulators and once again establish the desired test environment.

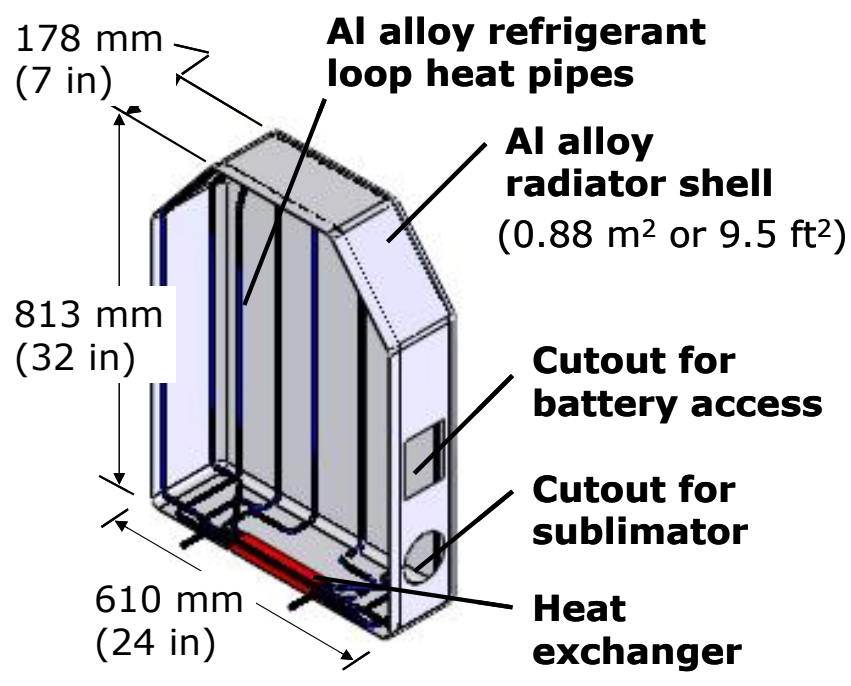

Figure 4. Layout of the radiator.

The RAFT-X weighs $8.63 \mathrm{~kg}(19.03 \mathrm{lbm})$ and Table 1 presents the mass of the major components. The radiator and heat exchanger components are the most massive. In addition, TDA estimated that $8.80 \mathrm{~kg}(19.4$ $\mathrm{lbm}$ ) could be saved by removal of the internal support structure, the EMU thermal protection garment and covers for the secondary oxygen pack, water tank and upper shield. As a result TDA expects a net system savings of $0.17 \mathrm{~kg}(0.36 \mathrm{lbm})$ by implementing the RAFT-X concept.

Table 1. RAFT-X mass breakdown.

\begin{tabular}{|l||c|c|}
\hline Component & Mass, kg (lbm) & $\mathbf{C}_{\mathbf{p}, ~ J / k g-C}$ \\
\hline \hline $\begin{array}{l}\text { Radiator w/ emissive } \\
\text { paint, loop heat pipes } \\
\text { and equipment mounts }\end{array}$ & $5.11(11.27)$ & 896 \\
\hline $\begin{array}{l}\text { MLI and aerogel } \\
\text { insulations }\end{array}$ & $1.81(3.99)$ & 1046 \\
\hline Heat exchanger & $1.48(3.26)$ & 385 \\
\hline Refrigerant & $0.23(0.50)$ & 1050 \\
\hline Total RAFT-X mass & $8.63(19.03)$ & \\
\hline \hline
\end{tabular}

Twenty-four Type $T$ adhesive thermocouples were attached to the RAFT-X radiator surface as shown in Figure 5. Two dual-element thermistor probes with 44033 elements measured the heat exchanger inlet and outlet water temperatures. Several thermocouples were also attached to the water lines and heat exchanger structure. An absolute pressure transducer monitored the water pressure. A differential strain-gauge pressure sensor measured the pressure drop across the heat exchanger.

Four (4) radiator mount points were provided to install the RAFT-X in the chamber. Each has a $1 / 4$-inchdiameter mounting hole. AN $37^{\circ}$ flare fittings were provided for fluid connections. Six (6) Aeroglaze coated and instrumented aluminum coupons were prepared to survey the chamber environment during tests. 


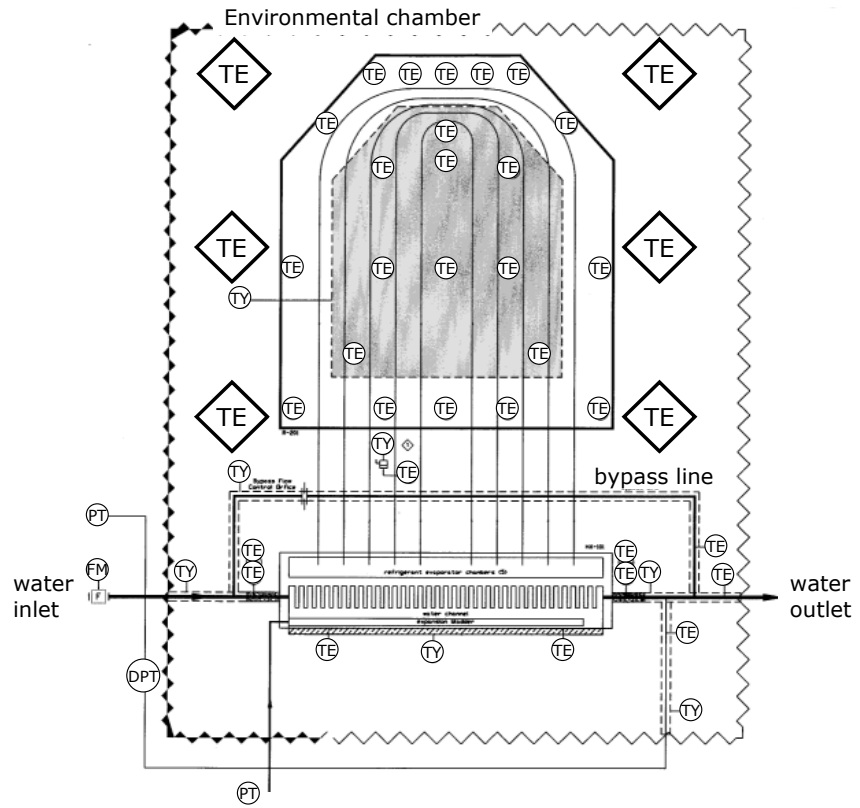

Figure 5. RAFT-X test article instrumentation layout.

\section{TEST SETUP AND FACILITY DESCRIPTION}

The NASA Johnson Space Center (JSC) Environmental Chamber $E$ test facility was used to determine the performance in Lunar and Mars environments (Figure 6). It has usable dimensions of $1.4 \mathrm{~m}$ diameter $\times 2.9 \mathrm{~m}(\phi 4.6$ $\mathrm{ft} \times 9.5 \mathrm{ft}$ ) and has liquid nitrogen cooled walls to lower the temperature to $-173^{\circ} \mathrm{C}\left(-280^{\circ} \mathrm{F}\right)$. Infrared heat lamps were powered to warm the chamber up to $38^{\circ} \mathrm{C}\left(100^{\circ} \mathrm{F}\right)$. The chamber pressure was evacuated down to $10^{-4} \mathrm{~Pa}$ ( 10 $10^{-6}$ torr) to simulate low earth orbit and Lunar conditions. Reduced pressures between vacuum and local atmospheric pressure were attained with a purge flow. JSC pressurized the chamber to $1333 \mathrm{~Pa}$ (10 torr) with argon to simulate the thermal conductance of the Mars atmosphere. Numerous feedthroughs provided instrumentation, gas and fluid delivery, electric power and mechanical actuation. An in-house Data Acquisition and Recording System (DARS) recorded and stored the data at $1 \mathrm{~Hz}$ with 16-bit precision. All channels were sampled sequentially at a $50 \mathrm{kHz}$ clock speed. LabView operated through National Instruments boards to control the facility and test article.

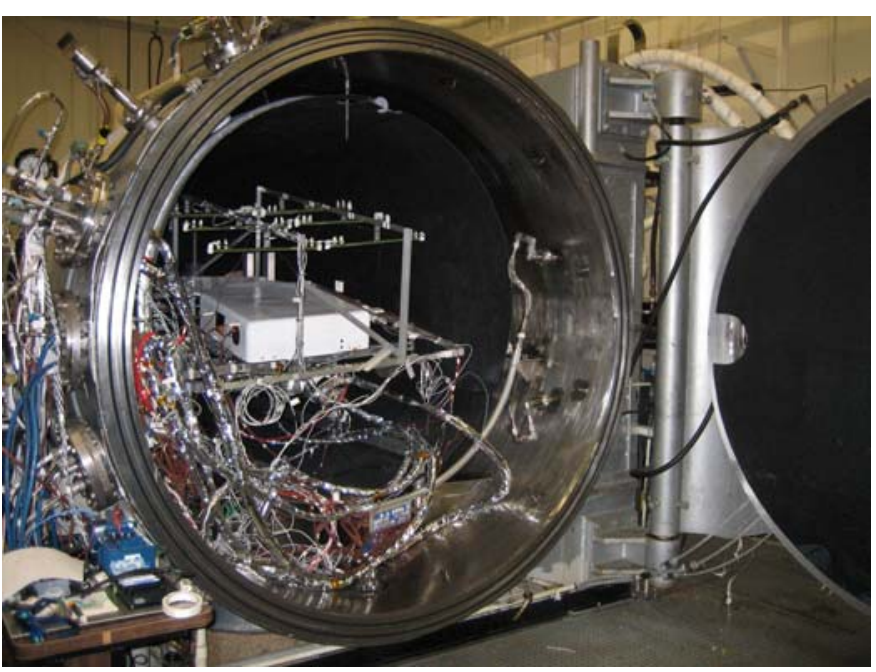

Figure 6. NASA JSC Chamber E with the RAFT-X installed at 10 degrees angle of inclination for the Lunar environment.

NASA JSC subjected the RAFT-X to various sink temperatures and heat loads in order to simulate astronaut metabolic loading in Lunar and Mars EVA environments. The objective of each test point was to determine the RAFT-X heat rejection capability at steady state conditions.

De-ionized water was continuously pumped through the heat exchanger at flow rates between 4.5 and $90 \mathrm{~kg} / \mathrm{h}$ (10 and $200 \mathrm{lbm} / \mathrm{h}$ ) and at a pressure of $207 \mathrm{kPa}(30$ psia). A Micro Motion ${ }^{\mathrm{TM}}$ coriolis flow meter measured the water flowrate. All of the water supply lines within the chamber were heat traced and covered with vacuum compatible radiative insulation in order to prevent freezing. Power to the heat tracing was remotely controlled and monitored.

Type $T$ thermocouples measured the temperature of the chamber cooling shroud that was also assumed to be the reference sink temperature when the IR lamps were off. In addition, six more Type $\mathrm{T}$ thermocouples were attached to coupons suspended with the centers about $2.5 \mathrm{~cm}$ (1 in) from the radiator to provide a continuous survey of the Chamber $E$ environment during the tests with the IR lamps powered.

The NASA JSC Systems Test Branch built the RAFT-X test article test stand. This structural support was insulated to thermally isolate it from the test article, and was designed to not interfere with the environmental conditioning. In addition, the support structure provided attitude control in two planes (both inclination and lateral tilt as sketched in Figure 7). The angles of inclination to simulate Lunar and Mars gravities are $10^{\circ}$ and $20^{\circ}$ at earth gravity, respectively. Unfortunately, the servomotor for the angle of inclination failed during the test program. Thus, all tests were conducted with the radiator at $10^{\circ}$ (the position to simulate a Lunar gravity). 


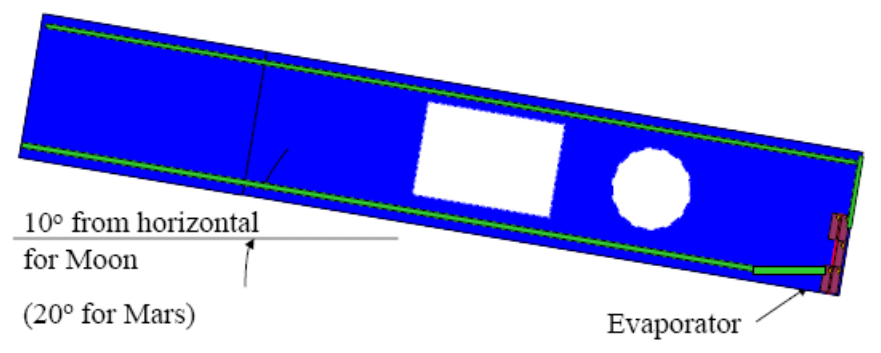

Side view

a) inclination angles to simulate Lunar and Mars gravities

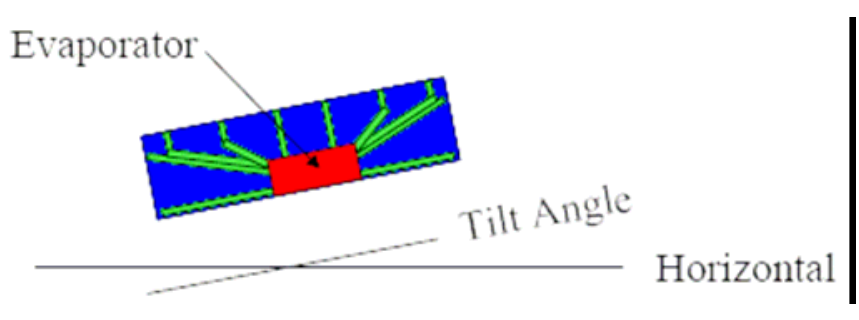

b) lateral tilt to simulate astronaut lean

Figure 7. Test article positioning relative to earth's gravity vector to simulate Lunar and Mars gravities.

Similarly, the lateral tilt angles of $2.5^{\circ}$ and $5^{\circ}$ corresponded to the maximum $15^{\circ}$ angle that an astronaut may lean without falling over in Lunar and Mars gravities, respectively. These were simulated to demonstrate radiator operation independent of the radiator and heat exchanger position relative to the gravity vector.

\section{TEST RESULTS AND DISCUSSION}

The overall test objective was to demonstrate good thermal heat rejection from a freeze tolerant radiator system over a broad range of operating conditions. Several tests were conducted to measure the RAFT-X performance in Lunar and Mars environments with rejection temperatures from +38 down to $-170^{\circ} \mathrm{C}(+100$ to $-275^{\circ} \mathrm{F}$ ). A hot environment test showed that the radiator does not transfer heat from the environment back to the astronaut. Thermal cycle tests showed the ability of the RAFT-X to adjust its heat rejection to the input load, which was varied from 90 to $250 \mathrm{~W}$ (300 to $850 \mathrm{Btu} / \mathrm{h})$.

We conducted the performance tests outlined in Table 2 with the radiator in several geometric orientations, and at several water flow rates and inlet temperatures, and while rejecting heat to nominal temperatures in both Lunar and Mars atmospheres. Freeze-thaw cycle testing was conducted by reducing the water flow to the heat exchanger to $9.1 \mathrm{~kg} / \mathrm{h}(20 \mathrm{lbm} / \mathrm{h})$ to allow the heat exchanger to freeze, then increasing the flow to about $20 \mathrm{~kg} / \mathrm{h}(\sim 45 \mathrm{lbm} / \mathrm{h})$ for 60 minutes to measure the low power heat rejection of the partially frozen heat exchanger and then return the flow to $90 \mathrm{~kg} / \mathrm{h}(200$ $\mathrm{lbm} / \mathrm{h}$ ) for 30 minutes to thaw it back out. The cycle was repeated two (2) times back to back to demonstrate freeze tolerance without failure.

In addition, there were a number of single point failure tests to run. A hot environment test was performed to ensure that the radiator does not transfer heat from the environment to the astronaut. The performance degradation due to the loss of a heat pipe was also determined. For this test, the refrigerant was remotely vented from a single loop heat pipe to simulate a leak due to micrometeoroid impact. NASA JSC also simulated the freeze trap scenario in the heat exchanger due to water pump failure. Afterwards, test personnel thawed the heat exchanger and repeated a maximum heat rejection test to demonstrate full recovery without loss of performance.

The tests were conducted in the order outlined in Table 2 , with the exception of Test Point L6, which was skipped after completion of L4 and L5 thermal cycles. The water inlet temperature was allowed to differ from the target values by up to $\pm 6^{\circ} \mathrm{C}\left( \pm 10^{\circ} \mathrm{F}\right)$. In Table 3 we provide the actual test values along with the original targets. 
Table 2. RAFT-X Preliminary Test Points.

\begin{tabular}{|c|c|c|c|c|c|}
\hline \multirow[t]{2}{*}{ TEST TYPE } & \multirow[t]{2}{*}{ TEST PT. DESCRIPTION } & \multicolumn{2}{|c|}{ CHAMBER ENVIRONMENT } & \multirow[t]{2}{*}{$\mathrm{T}_{\mathrm{H} 2 \mathrm{O}}\left({ }^{\circ} \mathrm{C}\right)$} & \multirow{2}{*}{$\begin{array}{l}\text { WATER } \\
\text { FLOWRATE } \\
(\mathrm{kg} / \mathrm{h})\end{array}$} \\
\hline & & DESCRIPTION & $\mathrm{T}\left({ }^{\circ} \mathrm{C}\right) / \mathrm{P}(\mathrm{Pa})$ & & \\
\hline Hot Environment & G1. Heat Gain Test & Ambient & +38/Ambient & 18 & 90.7 \\
\hline $\begin{array}{l}\text { Performance Tests, Lunar } \\
\text { (Steady State) }\end{array}$ & $\begin{array}{l}\text { L1. Max Heat Rej, No Tilt } \\
\text { L2. Max Heat Rej, Lat Tilt }\end{array}$ & $\begin{array}{l}\text { Cold Lunar } \\
\text { Cold Lunar }\end{array}$ & $\begin{array}{l}-156 / \mathrm{HV} \\
-156 / \mathrm{HV}\end{array}$ & $\begin{array}{l}18 \\
18\end{array}$ & $\begin{array}{l}90.7 \\
90.7\end{array}$ \\
\hline $\begin{array}{l}\text { Life Cycle Tests } \\
\text { (Low heat lead for } 60 \mathrm{~min} . \text {, } \\
\text { high heat load for } 30 \mathrm{~min} .)\end{array}$ & $\begin{array}{l}\text { L9. Steady-state at low } \\
\text { power } \\
\text { L4. Freeze/Thaw, cycle } 1 \\
\text { L5. Freeze/Thaw, cycle } 2 \\
\text { L6. Cycle } 3 \text { if needed } \\
\text { L3. Avg Heat Rej, No Tilt }\end{array}$ & $\begin{array}{l}\text { Cold Lunar } \\
\text { Cold Lunar } \\
\text { Cold Lunar } \\
\text { Cold Lunar } \\
\text { Nominal Lunar }\end{array}$ & $\begin{array}{l}-156 \mathrm{HV} \\
-156 / \mathrm{HV} \\
-156 / \mathrm{HV} \\
-156 / \mathrm{HV} \\
-34 / \mathrm{HV} \\
\end{array}$ & $\begin{array}{c}24 \\
24 / 18 \\
24 / 18 \\
24 / 18 \\
18 \\
\end{array}$ & $\begin{array}{c}4.5-18.5 \\
4.5 / 90.7 \\
4.5 / 90.7 \\
4.5 / 90.7 \\
90.7 \\
\end{array}$ \\
\hline $\begin{array}{l}\text { Performance Tests, Mars } \\
\text { (Steady State) }\end{array}$ & $\begin{array}{l}\text { M1. Max Heat Rejection } \\
\text { M2. Max Heat Rej, Lat Tilt } \\
\text { M3. Avg Heat Rejection }\end{array}$ & $\begin{array}{l}\text { Cold Mars } \\
\text { Cold Mars } \\
\text { Nominal Mars } \\
\end{array}$ & $\begin{array}{c}-100 / 1333 \\
-100 / 1333 \\
-45 / 1333 \\
\end{array}$ & $\begin{array}{l}18 \\
18 \\
18 \\
\end{array}$ & $\begin{array}{l}90.7 \\
90.7 \\
90.7 \\
\end{array}$ \\
\hline $\begin{array}{l}\text { Loss of Single Heat Pipe } \\
\text { Steady State Test, Mars }\end{array}$ & $\begin{array}{l}\text { M4. Degraded Max Heat } \\
\text { Load }\end{array}$ & Cold Mars & $-100 / 1333$ & 18 & 90.7 \\
\hline $\begin{array}{l}\text { Loss of Single Heat Pipe } \\
\text { Steady State Test, Lunar }\end{array}$ & $\begin{array}{l}\text { L7. Degraded Max Heat } \\
\text { Load }\end{array}$ & $\begin{array}{l}\text { Cold Lunar } / 4 \\
\text { hrs }\end{array}$ & $-156 / \mathrm{HV}$ & 18 & 90.7 \\
\hline Pump Failure Simulation & $\begin{array}{l}\text { L8. Freeze-up Test During } \\
90 \text { min EVA Emergency }\end{array}$ & $\begin{array}{l}\text { Cold } \\
\text { Lunar/TBD }\end{array}$ & $-156 / \mathrm{HV}$ & $\mathrm{N} / \mathrm{A}$ & 0 \\
\hline
\end{tabular}

Table 3. Actual test conditions.

\begin{tabular}{|c|c|c|c|c|c|c|c|c|c|}
\hline \multirow[t]{2}{*}{ Test Pt } & \multicolumn{2}{|c|}{$\begin{array}{l}\text { Chamber } \\
\text { Environment }\end{array}$} & \multicolumn{2}{|l|}{ Water } & \multicolumn{5}{|l|}{ RAFT-X } \\
\hline & $\mathrm{T},{ }^{\circ} \mathrm{C}$ & $\mathrm{P}, \mathrm{Pa}$ & $\mathrm{m}, \mathrm{kg} / \mathrm{h}$ & $\mathrm{T}_{\text {inlet }},{ }^{\circ} \mathrm{C}$ & $\Delta \mathrm{T}_{\text {HX water }},{ }^{\circ} \mathrm{C}$ & $\mathrm{T}_{\mathrm{HX}},{ }^{\circ} \mathrm{C}$ & $\mathrm{T}_{\mathrm{R}},{ }^{\circ} \mathrm{C}$ & $Q_{H X}, W$ & $Q_{R}, W$ \\
\hline G1 & +35 & "101325t & 86.2 & 1818.4 & 0.12 & 19 & 39 & 12 & 21 \\
\hline L1 & -168 & $1.3 \times 10^{-3}$ & 86.2 & 18.5 & 2.24 & 12.1 & -2.9 & 199 & 232 \\
\hline L2 & -168 & $0.72 \times 10^{-3}$ & 85.3 & 18.5 & 2.28 & 11.8 & -3.5 & 200 & 230 \\
\hline L9 & -161 & $0.69 \times 10^{-3}$ & 17.2 & 24.6 & 15.50 & -16.5 & -38.1 & 88 & 129 \\
\hline L4 & -155 & $0.68 \times 10^{-3}$ & $17.2-88.0$ & 30.2 & $2.72^{1}$ & $18.6^{1}$ & $5.6^{1}$ & $248^{1}$ & $260^{1}$ \\
\hline L5 & -170 & $0.69 \times 10^{-6}$ & $9.5-89.8$ & 23.3 & $2.45^{1}$ & $14.1^{1}$ & $-1.4^{1}$ & $228^{1}$ & $238^{1}$ \\
\hline L6 & ----- & ------ & ------ & ----- & ----- & ------ & - ---- & ----- & ------ \\
\hline L3 & -32 & $0.68 \times 10^{-6}$ & 91.6 & 18.9 & 1.56 & 9.5 & 6.8 & 149 & 123 \\
\hline M1 & -165 & 1290 & 90.3 & 18.4 & 2.57 & 6.8 & -5.3 & 241 & 223 \\
\hline M2 & -166 & 1310 & 89.8 & 18.4 & 2.64 & 6.6 & -4.8 & 247 & 225 \\
\hline M3 & -51 & 1310 & 90.3 & 18.6 & 1.79 & 10.2 & 2.6 & 168 & 151 \\
\hline M4 & -168 & 1360 & 89.8 & 18.4 & 2.57 & 6.8 & -7.1 & 239 & 218 \\
\hline L7 & $\begin{array}{l}-171 \\
\end{array}$ & $0.51 \times 10^{-3}$ & 89.4 & 19.1 & 2.36 & 10.2 & -3.9 & 219 & 229 \\
\hline L8 & -168 & $0.69 \times 10^{-3}$ & 0 & ----- & ----- & -20 & -59 & ----- & 104 \\
\hline
\end{tabular}

${ }^{1}$ during thaw at high flow rate

\section{HOT ENVIRONMENT}

The hot environment test, test point G1, was conducted to ensure that the radiator will not transfer heat from the environment to the astronaut. The chamber was heated to $+38^{\circ} \mathrm{C}\left(+100^{\circ} \mathrm{F}\right)$ as measured by the environmental coupon thermocouples. This temperature was well above the water inlet temperatures to the test article.
The chamber pressure was left at local ambient. No increase in the water outlet temperature was observed for the duration of the test.

MAXIMUM HEAT REJECTION (0 AND 2.5 LATERAL TILT) 
Test points L1 and L2 were conducted to determine the maximum steady state heat rejection rate of the RAFT-X test article in simulated Lunar thermal environment conditions (hard vacuum and $-170^{\circ} \mathrm{C}$ ). In test $\mathrm{L} 2$ the radiator was laterally tilted to $2.5^{\circ}$. The heat rejection rate was $232 \mathrm{~W}(792 \mathrm{Btu} / \mathrm{h})$ for L1 and $230 \mathrm{~W}$ (785 $\mathrm{Btu} / \mathrm{h}$ ) for L2; essentially identical results and well within the average uncertainty of $\pm 15 \mathrm{~W}( \pm 50 \mathrm{Btu} / \mathrm{h})$.

\section{STEADY-STATE LUNAR AND MARS PERFORMANCE TESTS}

Results from tests L1-L6, L9 and M1-M3 were used to calculate the steady-state heat rejection performance of the RAFT-X. Test points M1 and M2 demonstrated the maximum heat rejection for the RAFT-X test article in Mars cold thermal environment conditions, and test point M3 demonstrated the average heat rejection of RAFT-X in a nominal Mars thermal environment.

The heat rejected by the radiator appears to exceed that transferred by the heat exchanger for most test points in the simulated Lunar environment (Figure 8). The shroud temperatures were $70^{\circ} \mathrm{C}$ cooler than the environmental coupon temperatures during the cold Lunar tests. Thus, the 'true' environmental temperature may lie somewhere between the two.

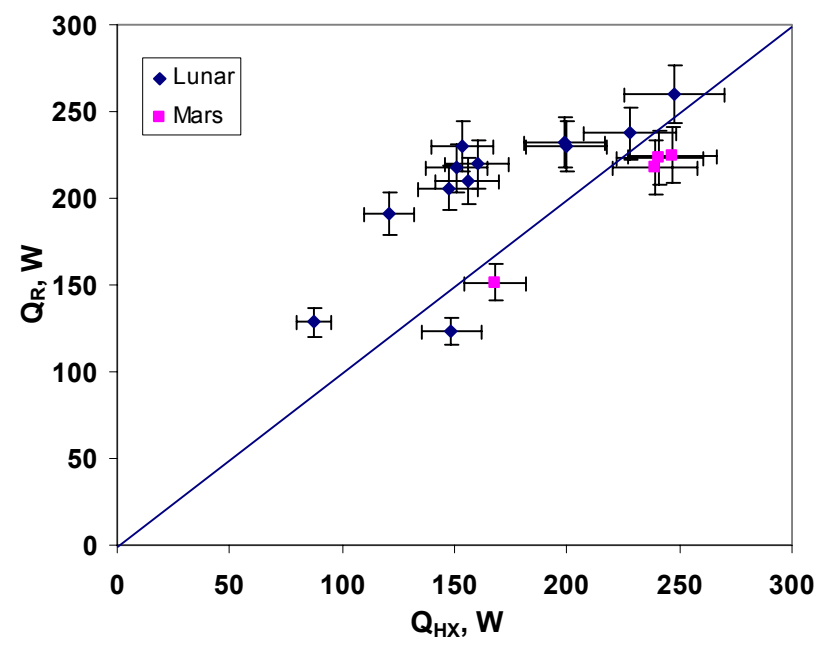

Figure 8. Heat rejected from the radiator vs. heat transferred by the heat exchanger.

For the tests in the simulated Mars environment the heat rejected by the radiator was always less than that transferred by the heat exchanger (Figure 8 and Figure 9). This is not unexpected, since natural convection and gas conduction terms begin to become important. Approximately $10 \%$ of the total heat appears to have been lost by these mechanisms.

The thermal conductivities for Argon at -50 and $-168^{\circ} \mathrm{C}$ are 0.01354 and $0.00668 \mathrm{~W} / \mathrm{m}-\mathrm{K}$, respectively. Knowing that the coupons were suspended about $2.5 \mathrm{~cm}$ (1 in) from the radiator we could determine the conduction loss. We also calculated the change in heat rate due to the heat capacity of the radiator using our experimentally determined value for thermal mass of $2.0 \mathrm{~W}-\mathrm{h} / \mathrm{C}(3.8$ Btu/F). We assumed the environment to be at "steadystate" when the temperature change of the coupons was less than $0.5^{\circ} \mathrm{C}\left(1^{\circ} \mathrm{F}\right)$ in a 10 -minute period. The corresponding temperature change of the radiator was less than $0.05^{\circ} \mathrm{C}\left(0.1^{\circ} \mathrm{F}\right)$, which resulted in a negligible change in the heat absorbed or given off by the radiator $(<0.6 \mathrm{~W})$. Finally, we can infer that the convective heat loss is the difference between the heat transferred by the heat exchanger and that radiated by the radiator after correction for the conduction loss term. For tests in the Mars environment, both convection and conduction will be present and our data shows that these mechanisms are about $10 \%$ of the total heat rejection and radiation comprises the remainder.

In our tests the RAFT-X rejected up to $260 \mathrm{~W}(890$ Btu/h). Throttling the water flow rate made little difference in heat rejection from the radiator as can be seen in Figure 9a (i.e. radiators reject heat at nearly a constant rate unless radiator surface area or the heat exchanger can be turned down). The temperature difference between the heat exchanger inlet and outlet flows increased as the flow rate was decreased to keep

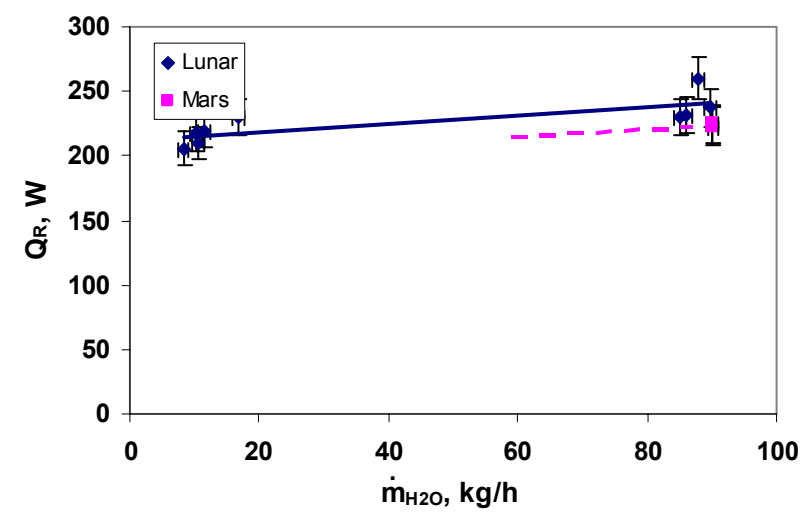

a) radiative heat rejection

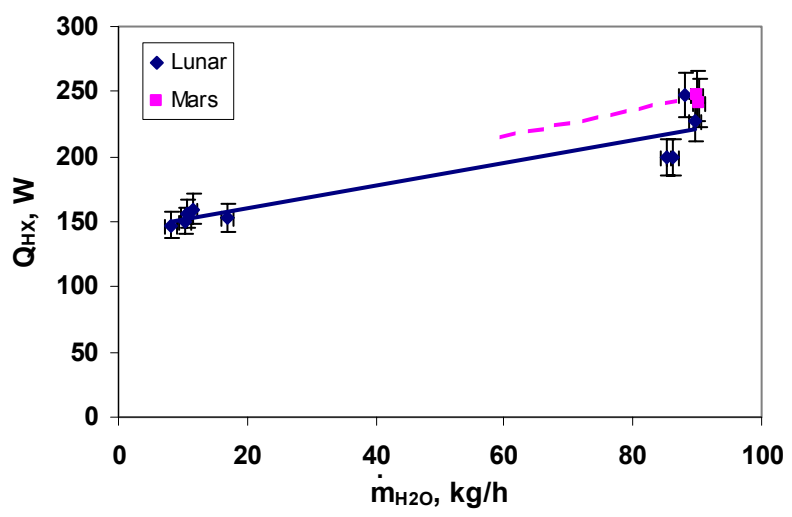

b) heat transferred by the heat exchanger

Figure 9. Heat rejection rates for the radiator and heat exchanger in simulated Lunar and Mars environments. Fully thawed heat exchanger (i.e. no partial freeze data included). 
the $\mathrm{mc}_{\mathrm{p}} \Delta \mathrm{T}$ term almost constant.

Examination of Figure $9 a$ and $b$ shows that the radiator rejects more heat than the heat exchanger at low flows. Upon reduction in water flow, the heat exchanger first cools down, while the radiator is still relatively warm and must reject a greater amount of heat to the environment to cool its thermal mass. Eventually, the radiator cools down as well and better matches the heat rejection from the heat exchanger. Conversely, if the water flow rate is increased, then the heat exchanger transfers a lot of heat, some of which must go into the thermal mass of the radiator to warm it up before once again a match of the heat transfer occurs. We observed that the heat exchanger responded reasonably quickly to changes in heat load, but the radiator adjusted more slowly due to its greater thermal mass. The data shows very little effect of the Lunar and Mars environments on the heat transfer rate from the heat exchanger, but as expected the amount of heat rejected by the radiator falls in warmer environments.

\section{LIFE CYCLE TESTS}

Test points L4, L5 and L6 demonstrated the freeze and thaw cycle capability for the RAFT-X test article in Lunar thermal environment conditions under low heat load conditions. Freezing was allowed to occur on the water side of the test article heat exchanger at $4.5-9 \mathrm{~kg} / \mathrm{h}(10-$ $20 \mathrm{lbm} / \mathrm{h}$ ) water flowrate, followed by thawing at $90 \mathrm{~kg} / \mathrm{h}$ $(200 \mathrm{lb} / \mathrm{h})$ water flowrate for about 30 minutes for each test point. The cycle was repeated to demonstrate freeze tolerance without failure. Since the heat exchanger froze up at $4.5 \mathrm{~kg} / \mathrm{h}(10 \mathrm{lbm} / \mathrm{h})$, we increased flow to $18 \mathrm{~kg} / \mathrm{h}(40 \mathrm{lbm} / \mathrm{h})$ after the freeze process began. This allowed us to operate the heat exchanger in a partially frozen condition. The environmental chamber heat lamps were turned on to thaw the heat exchanger if we completely froze it up.

In Figure 10 we show the RAFT-X heat exchanger performance during heat rejection to a cold Lunar environment (chamber conditions of $-170^{\circ} \mathrm{C}\left(-270^{\circ} \mathrm{F}\right)$ and hard vacuum). When fully thawed the heat rejection was throttled from 250 to $160 \mathrm{~W}(850 \mathrm{Btu} / \mathrm{h}$ to $550 \mathrm{Btu} / \mathrm{h})$ in this environment (the upper curve). In our experiments the heat exchanger began to freeze when the flow was reduced to $9 \mathrm{~kg} / \mathrm{h}(20 \mathrm{lbm} / \mathrm{h})$ or less. Once a layer of ice was formed, the water flow passages quickly froze. Only the bypass tube remained open, which in practice would flow water to the sublimator to provide the needed cooling. However, by increasing the water flow before the passages completely froze we could then operate along the lower curve to substantially reduce the heat load. The heat rejection at $18 \mathrm{~kg} / \mathrm{h}(40$ $\mathrm{lbm} / \mathrm{h}$ ) was reduced from 160 to $90 \mathrm{~W}$ (550 to $300 \mathrm{Btu} / \mathrm{h}$ ) during partial freeze operation.

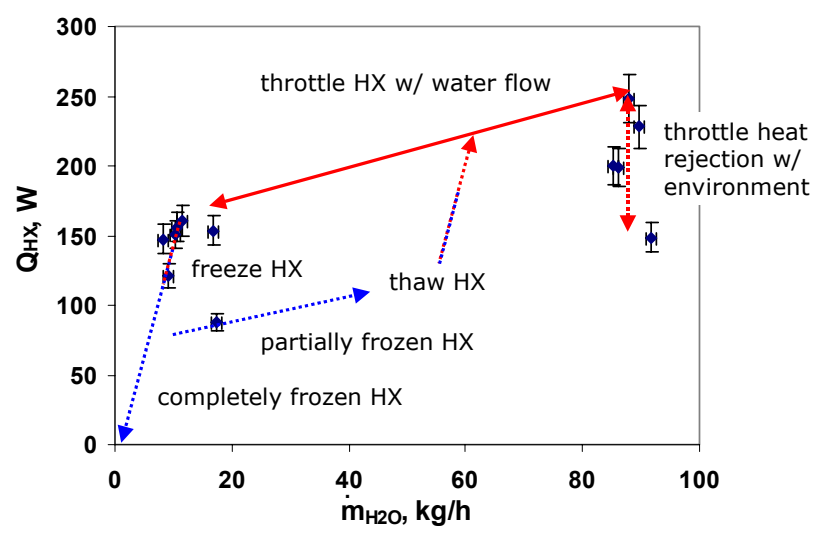

Figure 10. RAFT-X heat exchanger performance data from tests conducted in the NASA JSC Chamber $\mathrm{E}$ thermal vacuum facility.

As shown in Figure 11, the radiator temperature quickly dropped once the heat exchanger began to freeze (just after 04:36 when the water flow was dropped to $5 \mathrm{~kg} / \mathrm{h}$ in Figure 11a). The heat rejection rate also fell as we previously showed in Figure 10. Once frozen the water flow was bypassed around the heat exchanger, even when the water flow was raised back to $90 \mathrm{~kg} / \mathrm{h}$.

After the heat exchanger was completely frozen in cycle 1 , it was then thawed by turning on the heat lamps to warm the system. We then proceeded to conduct a second freeze / thaw cycle. The heat exchanger began to freeze just after 08:00 when the water flow was lowered to $10 \mathrm{~kg} / \mathrm{h}$ (Figure 11b). At about 08:15 the water flow was increased to about $18 \mathrm{~kg} / \mathrm{h}$ to obtain the heat rejection performance while the heat exchanger was partially frozen (i.e. part of the water flow could still pass through the heat exchanger to continue rejecting heat, albeit at a reduced level of about $90 \mathrm{~W}$ as can be seen in Figure 10). 


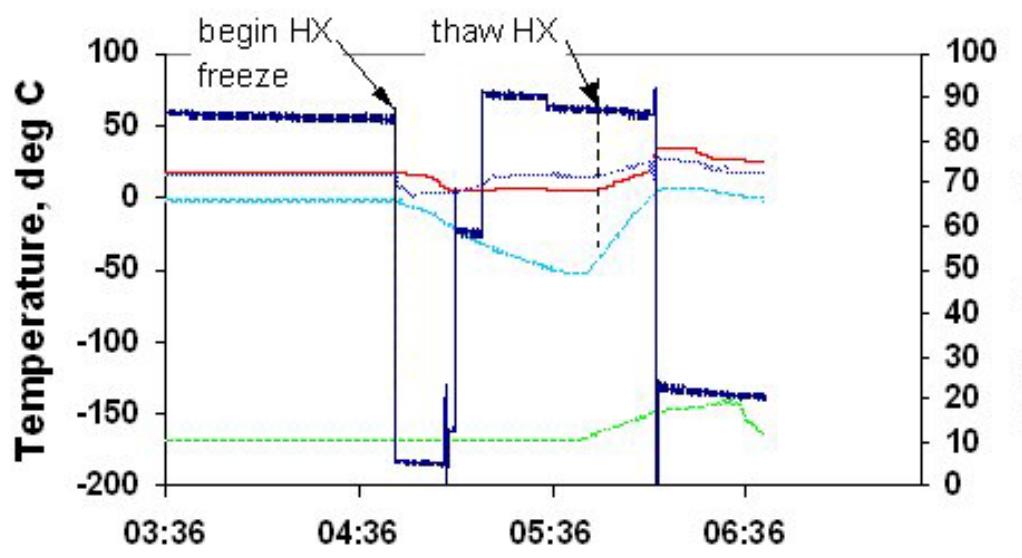

Time, hh:mm

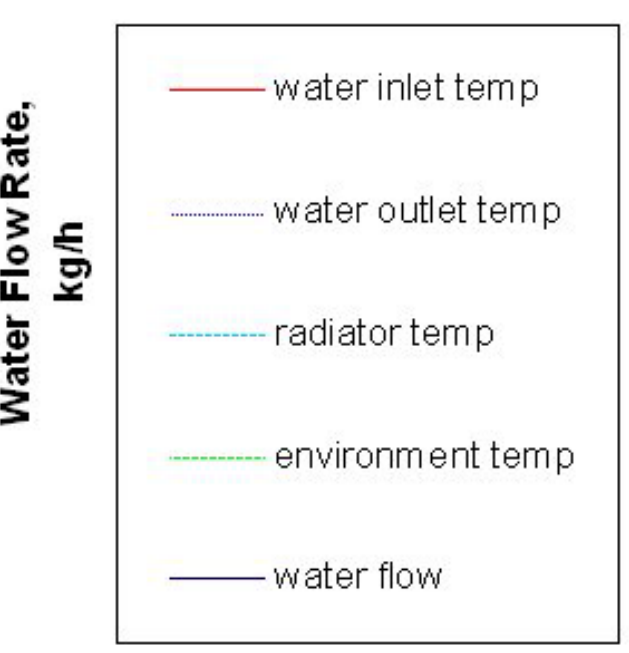

a) the first freeze / thaw cycle (completely frozen heat exchanger)
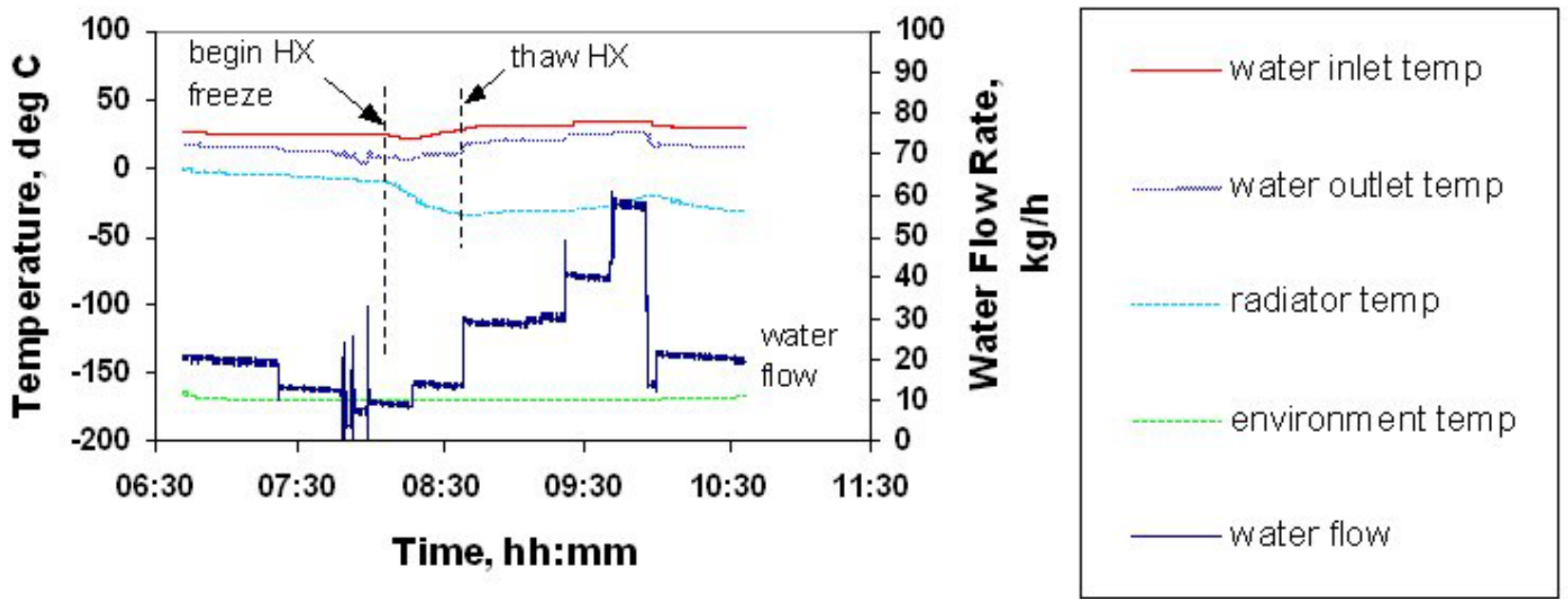

b) the second freeze / thaw cycle (partially frozen heat exchanger)

Figure 11. Freeze / thaw cycle time histories.

The thermal mass of the radiator was able to be determined from the cooldown period in the Lunar environment (Figure 12). The heat transfer from the heat exchanger was steady and the heat rejection from the radiator was only due to radiation (i.e. the convection and conduction terms were negligible).
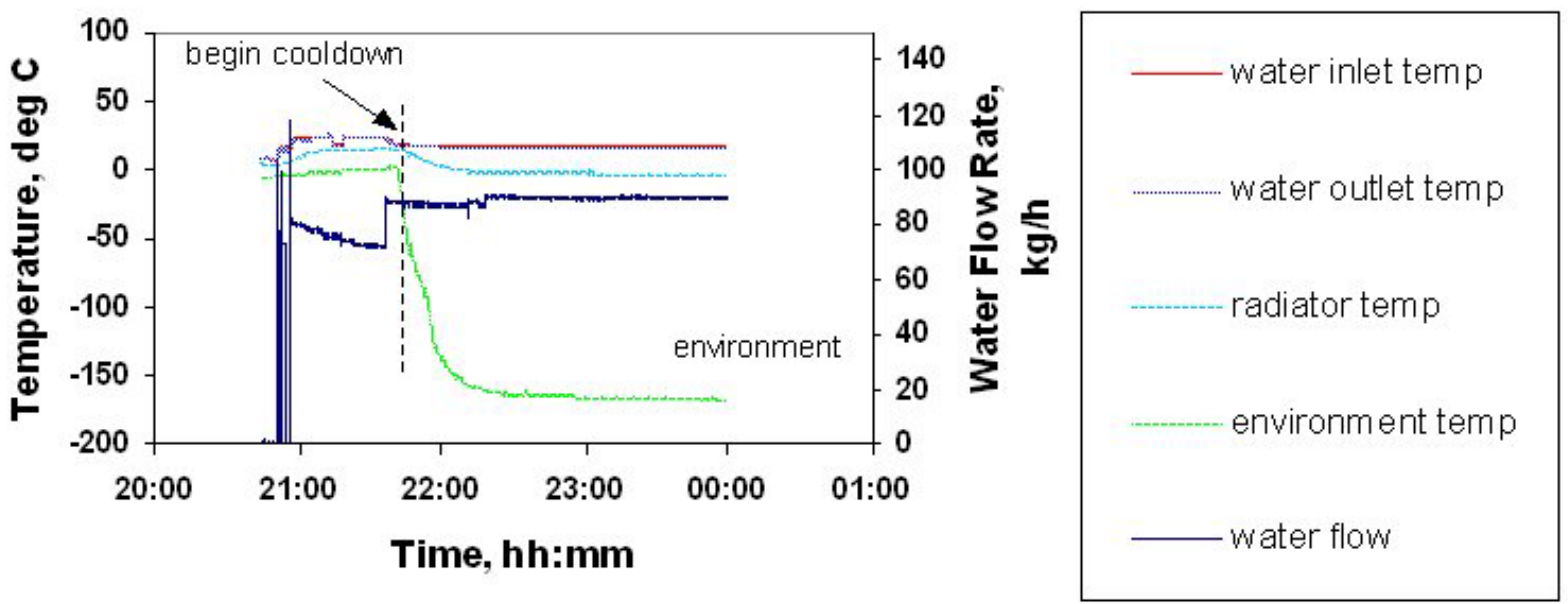

Figure 12. Chamber cooldown period used for thermal mass calculation. 
Using a finite-difference approximation to the heat rate equation (given below):

$$
m \cdot c_{p}=Q_{R} \cdot \frac{\Delta t}{\Delta T_{R}}
$$

we calculated the thermal mass to be $2.0 \mathrm{~W}-\mathrm{h} /{ }^{\circ} \mathrm{C}(3.8$ $\left.\mathrm{Btu} /{ }^{\circ} \mathrm{F}\right)$. Using the measured mass of $7.15 \mathrm{~kg}(15.76$ $\mathrm{lbm})$ for the radiator, insulation and refrigerant, the $\mathrm{c}_{p}$ was calculated to be $1005 \mathrm{~J} / \mathrm{kg}-\mathrm{C}(0.24 \mathrm{Btu} / \mathrm{lbm}-\mathrm{F})$. This is very reasonable, since the average specific heat was estimated to be $938 \mathrm{~J} / \mathrm{kg}-\mathrm{C}(0.224 \mathrm{Btu} / \mathrm{lbm}-\mathrm{F})$ using published specific heats and measured weights for each component. Only the mass of the heat exchanger was excluded.

\section{LOSS OF SINGLE HEAT PIPE}

For the Mars environment, test point M4 demonstrated the extent of performance degradation at the maximum heat load condition after the loss of a single heat pipe (the second loop from the center in Figure 5). The refrigerant was remotely vented at the beginning of the test using a heater (TY-201) to simulate a leak due to micrometeoroid impact. The heat rejection rate from the radiator fell from 225 to $218 \mathrm{~W}(768 \mathrm{Btu} / \mathrm{h}$ to $743 \mathrm{Btu} / \mathrm{h})$; only a $3 \%$ loss in performance despite losing one of the five loops and $20 \%$ of the refrigerant.

The vented heat pipe remained vented for the remainder of the test program. For the Lunar environment, test point L7 demonstrated the extent of performance degradation at the maximum heat load test condition with the loss of a single heat pipe. There was almost no difference in heat rejection rates (232 W for L1 vs. 229 W for L7).

\section{WATER PUMP FAILURE}

Test point L8 demonstrated the freeze trap scenario in the RAFT-X heat exchanger due to a pump failure. Water flow to RAFT-X was turned off for this simulation. Afterwards, the heat exchanger was thawed by (turning on both the heaters and water flow), and a maximum heat rejection test was repeated to ensure full recovery without the loss of performance. In addition, the environment IR lamps were powered up to assist in thawing. After thawing, the test point L1 was repeated to verify restart (approximately 1.5 hour test).

As it turned out we completely froze the heat exchanger twice during the life cycle tests while the water was still flowing. We also intentionally froze it during the Mars calibration run, since the water was turned off. Each time the heat exchanger was recovered by warming the chamber until thawed. The RAFT-X delivered the same performance after the freeze as before. Thus, the freeze tolerance of our heat exchanger was successfully demonstrated.

\section{POST-TEST INSPECTION OF THE RAFT-X TEST ARTICLE}

The AR3103 aerogel insulation was encapsulated with gray silicone impregnated fiberglass cloth (L-cloth), which was not good enough to contain the silica dust. Loose aerogel silica dust was everywhere inside the test article when opened up (Figure 13), which NASA JSC personnel had to vacuum it out just to be able to handle the interior of the test article. This is an issue that will need to be addressed in future work to keep from contaminating the crew and their quarters.

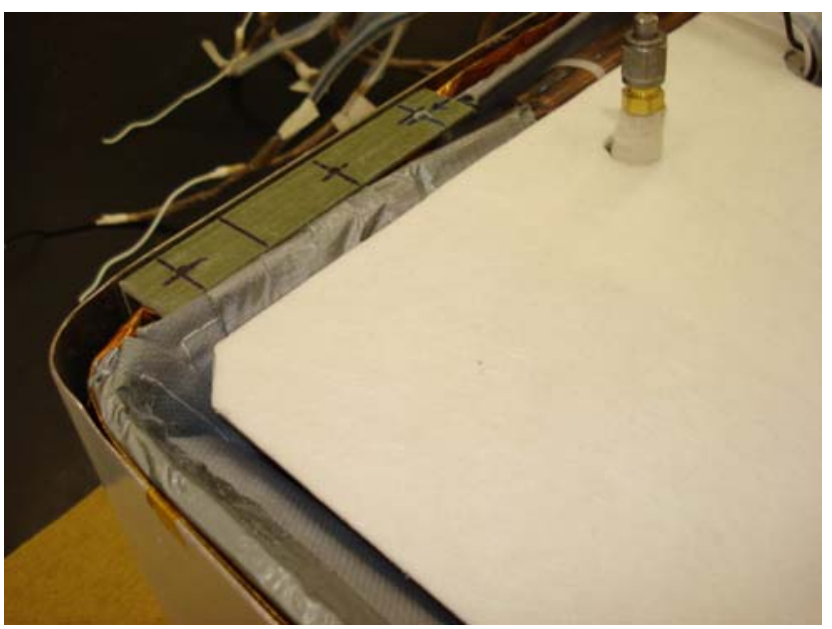

Figure 13. Post-test inspection revealing loose aerogel silica dust within the RAFT-X test article.

NASA JSC personnel also removed the aerogel blankets and $\mathrm{MLI}$ to inspect the thermocouples and equipment mounts. Only one of the thermocouples had come loose (TC 216 along the left side wall). This thermocouple data was excluded from the analysis.

\section{FINITE ELEMENT ANALYSIS OF RAFT-X IN LUNAR ENVIRONMENTS}

As described above, the thermal vacuum test showed the thermal performance for the RAFT-X unit in two different Lunar environments. At the conclusion of these tests, it was critical to quantify the performance of the radiator in several other Lunar environments. A geometrically equivalent finite element model (FEM) was created using MSC.Patran [7]. This model, shown in Figure 14 , included approximately 24,000 nodes with an average node spacing of 0.64 centimeters.

The first step taken after the model was built to ensure that it was an appropriate representation of the hardware used during the test. As a result, several calibration runs were completed for Lunar test point L1 and L3 to confirm that all of the model variables were accurately set to predict the performance of the radiator. The calibration runs showed excellent agreement with the 
test data for both L1 and L3. For the first Lunar run, L1, all of the nodal temperatures matched the equivalent thermocouple within $2.5^{\circ} \mathrm{C}$. The agreement for the second Lunar run, L3, was even better as all of the temperatures matched within $2^{\circ} \mathrm{C}$.

The aforementioned FEM showed excellent agreement with the two Lunar test points considered during the thermal vacuum test. From there, it was of paramount importance to the development team to better understand how the radiator would perform in varying thermal environments on the Lunar surface. In order to accomplish this goal, the FEM was analyzed for several different sun angles ranging from $0^{\circ}$ to $180^{\circ}$ in $10^{\circ}$ increments. The angles described above were measured off of the negative z-axis as shown in Figure 14. The sun was assumed to remain within the $y-z$ plane for the entire range of analyzed sun angles (and the crewmember view is along the positive z-axis). The thermal analysis included the calculation of the direct solar, solar albedo, and Lunar IR flux for all of the radiator surfaces. The Lunar IR emissivity and solar albedo were assumed to be 0.92 and 0.073 , respectively as suggested by Gilmore 2002 [8]. Likewise a solar constant for perihelion of $1422 \mathrm{~W} / \mathrm{m}^{2}$ was used for the thermal analysis. [8] The resulting heat dissipations for the varying solar angles are shown in Figure 15.

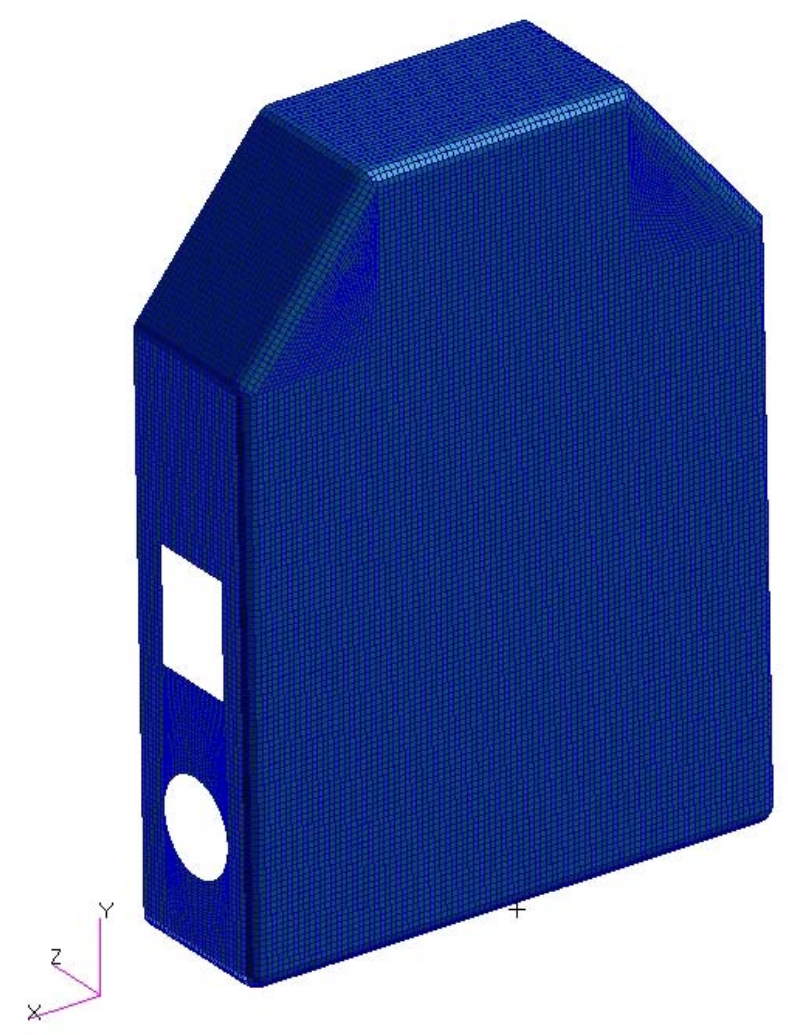

Figure 14. Finite element model used for posttest calibration and predictions.

Notice that there are no data for solar angles between $20^{\circ}$ and $150^{\circ}$. This is because the effective sink temperature is too high for the radiator to dissipate energy to the ambient environment. This is unique to the Lunar environment because the solar absorptivity is extremely high for the Lunar surface; effectively resulting in a very high incident IR flux on the radiator surface. As with any radiator, the RAFT-X has a relatively high IR emissivity $(\varepsilon \sim 0.90)$, which results in $90 \%$ of the incident IR flux being absorbed by the radiator surface. The other interesting phenomenon that is apparent from Figure 15 is that the resulting heat dissipation is higher for solar angles above $90^{\circ}$. As a reference point, compare the heat dissipation value for a solar angle of $0^{\circ}$ to that for a sun angle of $180^{\circ}$. Figure 15 clearly shows that the radiator is capable of dissipating much more energy at $180^{\circ}$. This is a result of the incident solar flux being lower at sun angles higher than $90^{\circ}$. For the purposes of this analysis, it was assumed that the crewmember would block all of the direct solar from impinging onto the radiator surfaces. Therefore, the only solar flux component remaining for sun angles above $90^{\circ}$ was the solar albedo.

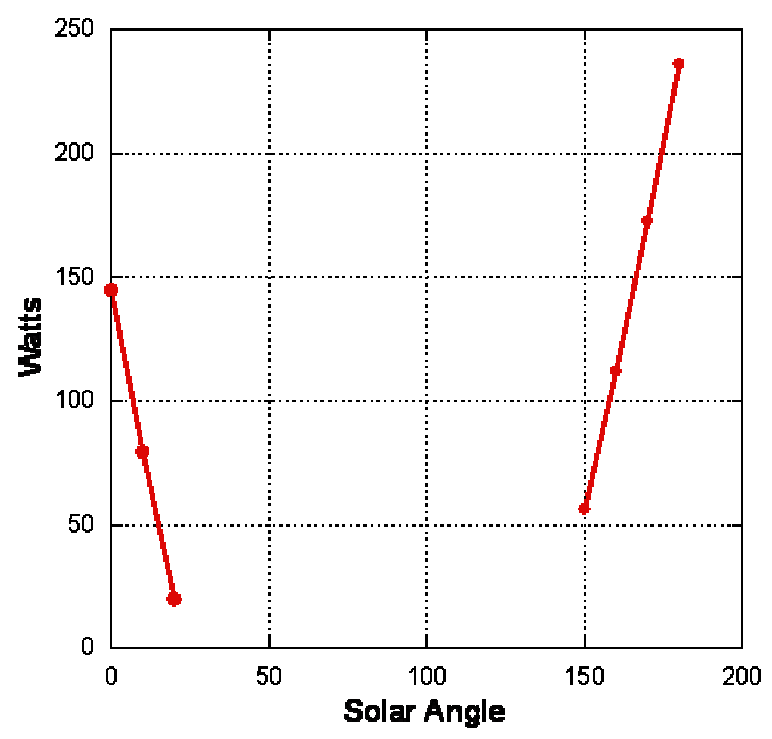

Figure 15. RAFT-X heat dissipation for varying Lunar solar angles.

\section{CONCLUSION}

In conclusion, a lightweight radiator and freeze tolerant heat exchanger was built that can reject heat from the astronaut and EMU by radiation. The available surface area of the EMU and the local environment determine the amount of heat that may be rejected. Extensive testing in the NASA JSC Chamber E Thermal Vacuum Facility showed that the RAFT-X performed very well. Up to $260 \mathrm{~W}$ (890 Btu/h) of heat were rejected in Lunar and Mars environments with temperatures as cold as $175^{\circ} \mathrm{C}$. The RAFT-X endured several freeze / thaw cycles and in fact, the heat exchanger was completely frozen three times without any apparent damage to the unit. We were also able to operate the heat exchanger in a partially frozen configuration to throttle the heat rejection rate from $160 \mathrm{~W}(550 \mathrm{Btu} / \mathrm{h})$ at low water flow rate down to $90 \mathrm{~W}(300 \mathrm{Btu} / \mathrm{h})$. Finally, the loss of a single loop heat pipe only degraded the heat rejection 
performance by about 2 to $5 \%$. These results conclusively show the robust heat rejection performance that the RAFT-X concept can provide to an astronaut during EVA.

The finite element model of the RAFT-X showed excellent agreement with the thermal vacuum tests performed at JSC. This calibrated model was used to predict the thermal performance of the radiator in varying Lunar thermal environments. The results of the FEM proved that the radiator is able to effectively dissipate energy in several operational scenarios including sun angles between $0^{\circ}$ and $20^{\circ}$ as well as between $150^{\circ}$ and $180^{\circ}$. Between $20^{\circ}$ and $150^{\circ}$, the effective sink temperature is too high for the radiator to dissipate energy to the ambient environment.

\section{ACKNOWLEDGMENTS}

The authors wish to thank the Systems Test Branch at NASA Johnson Space Center for test support of the Chamber $E$ facility. Further, TDA wishes to acknowledge the funding provided for RAFT-X development by the NASA Johnson Space Center (Contract \#NAS 9-03052).

\section{REFERENCES}

1. Thomas, G.A., "Packing factors for Portable Life Support Subsystems Based on Apollo and Shuttle Systems," Paper No. 932182, 23rd International Conference on Environmental Systems, Colorado Springs, CO, 12-15 July 1993.

2. Wilson, J.L. and B.M. Lawson, "Investigation into Venting and Non-venting in Space Station and Advanced EVA Technologies," Warrendale, PA. Society of Automotive Engineers, Inc., Special Publication Number SP-830, 1990.

3. Nabity, J., R. Copeland, G. Mason, K. Libberton, H. Paul, L. Trevino and R. Stephan, "Performance Testing of an Advanced Lightweight Freezable Radiator," SAE 2006-01-2232, $36^{\text {th }}$ International Conference on Environmental Systems, July 2006.

4. Williams, J.L., B.W. Webbon, and R.J Copeland, Advanced Extravehicular Protective Systems (AEPS) Study Detailed Technical Notes prepared by Vought Missiles and Space Company, LTV Aerospace Corporation, Dallas, Texas under Contract No NAS2-6022 for Ames Research Center, National Aeronautics and Space Administration, March 1973.

5. Cross, C., Trevino, L. and Laubach, J.G., "Thermal performance of the Radiator System," Society of Automotive Engineers, Inc. Paper No. 981672, $28^{\text {th }}$ International Conference on Environmental Systems, 1998.

6. Nabity, J., Copeland, R., Mason, G. and Trevino, L., "Advanced Lightweight Freeze Tolerant Radiator for the EMU," Habitation 2006 Conference, 5-8 Feb 2006. http://habitation.rutgers.edu/2006/presentations/sess ion_19/HLS139/TDA_Advanced_Radiator_Habitatio n_2006.ppt

7. MSC.Patran Thermal User's Guide Volume 1. Thermal/Hydraulic Analysis. 2001.

8. Gilmore, David G. Spacecraft Thermal Control Handbook. Volume 1: Fundamental Technologies. The Aerospace Corporation, 2002.

\section{CONTACTS}

\section{JAMES NABITY, TDA RESEARCH}

Mr. Nabity received a BS degree in Mechanical Engineering from the University of Nebraska in 1983 and his MS in Aeronautical Engineering from the Naval Postgraduate School in 1989. In 1996, Jim was elected a Naval Air Warfare Center Technical Fellow for his contributions to combustion research. He joined TDA's aerospace technology staff in 1999. Overall, he has 24 years experience in thermal systems, propulsion, combustion, flow stability, test methods and MEMS research and has published extensively in these areas. Jim may be reached at:

James Nabity, Principal Investigator

TDA Research, Inc

12345 W 52nd Ave

Wheat Ridge, CO 80033

(303) 940-2313 or nabity@tda.com

\section{LUIS TREVINO, NASA JOHNSON SPACE CENTER}

Luis Trevino is a part of the Advanced Extravehicular Activity Team at the NASA Johnson Space Center. He is the Thermal Subsystem manager for the development of the next generation Portable Life Support Systems that will be used with the Lunar and Martian space suits. He can be reached at luis.trevino-1@nasa.gov.

\section{DEFINITIONS, ACRONYMS AND ABBREVIATIONS}

\section{ACRONYMS}

EMU: Extravehicular Mobility Unit

EVA: Extravehicular Activity

IO: Input Output

LCG: Liquid Cooling Garment

PLSS: Portable Life Support System

RAFT-X: Radiator and Freeze Tolerant Heat Exchanger 


\section{NOMENCLATURE}

A surface area or cross-sectional flow area, $\mathrm{m}^{2}$ $\left(\mathrm{ft}^{2}\right)$

$\mathrm{C}_{\mathrm{p}}$ specific heat, $\mathrm{J} / \mathrm{kg}-\mathrm{K}(\mathrm{Btu} / \mathrm{lbm}-\mathrm{R})$

$\mathrm{C}_{\mathrm{v}} \quad$ flow coefficient

DPT differential pressure transducer

FEM finite element model

FM flow meter

$\mathrm{HX}$ heat exchanger

$\mathrm{LN}_{2} \quad$ liquid nitrogen

m mass, $\mathrm{kg}(\mathrm{lbm})$

$\dot{m} \quad$ mass flowrate, $\mathrm{kg} / \mathrm{h}(\mathrm{lbm} / \mathrm{h})$

$\Delta \mathrm{P} \quad$ pressure drop, $\mathrm{Pa}(\mathrm{psid})$

PT pressure transducer

Q heat rejection rate or power, W $(B t u / h)$
$\Delta \mathrm{t} \quad$ time difference

$\Delta \mathrm{T} \quad$ temperature difference

$\mathrm{T} \quad$ temperature, ${ }^{\circ} \mathrm{C}\left({ }^{\circ} \mathrm{F}\right)$

TE temperature element, either thermocouple or thermistor

TY temperature control

$\varepsilon \quad$ emissivity

$\rho \quad$ density, $\mathrm{kg} / \mathrm{m}^{3}\left(\mathrm{lbm} / \mathrm{ft}^{3}\right)$

$\sigma \quad$ Stefan-Boltzmann constant, 5.67E-08 W/m² $-\mathrm{K}^{4}$

Subscripts

bypass the heat exchanger bypass tube

$\mathrm{R} \quad$ radiator

$\infty \quad$ ambient surroundings, cold plate or sink 